\title{
A arquitetura curativa do Sanatório Santa Terezinha
}

\author{
The healing architecture of Santa Terezinha Sanatorium
}

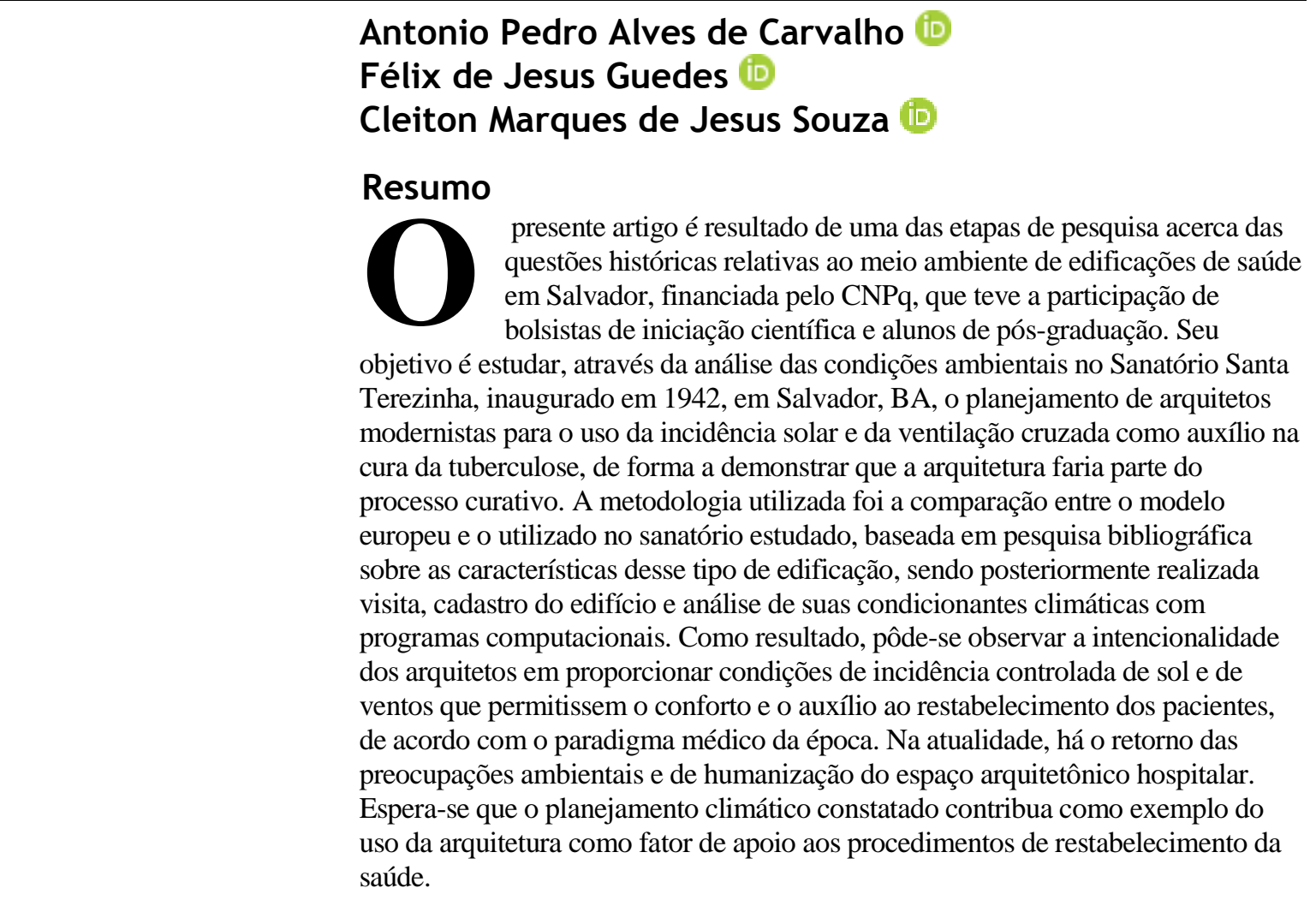

${ }^{1}$ Antonio Pedro Alves de Carvalho Universidade Federal da Bahia Salvador - BA - Brasil

${ }^{2}$ Félix de Jesus Guedes ${ }^{2}$ Universidade Federal da Bahia Salvador - BA - Brasil

${ }^{3}$ Cleiton Marques de Jesus Souza

${ }^{3}$ Universidade Federal da Bahia Salvador - BA - Brasil

Recebido em 05/12/19 Aceito em 05/03/20
Palavras-chave: Arquitetura hospitalar. Sanatórios. Modernismo. Conforto climático.

\section{Abstract}

This paper is the result of one stage of a research project on historical issues related to the environment of healthcare buildings in Salvador, Brazil, funded by $C N P q$, with the participation of undergraduate and postgraduate scholars. Its objective is to study, through an analysis of the environmental conditions at the Sanatorium Santa Terezinha, inaugurated in 1942, in Salvador, BA, the plans made by modernist architects for the use of solar incidence and cross ventilation as an aid in healing tuberculosis, in order to demonstratethat architecture can be part of the healing process. Themethodology of the investigation was to trace the history of the hospital, based on a review of the literature on the characteristics of this type of building, followed by a visit, a survey of the building and an analysis of its climate conditions using computer programs. That allowed the researchers to see evidence of the intentionality of the architects as they provide conditions of controlled incidence of sun and wind in order to enhance patients'comfort and recovery, according to the medical paradigm of the time. In the present day, environmental concerns and the humanisation of hospitals' architectural space are back on the agenda. The climate planning seen in this study will hopefully contribute as an example of the use of architecture as a factor to support the restoration of health.

Keywords: Hospital architecture. Sanatoria. Modernism. Climate confort. 


\section{Introdução}

O presente artigo é resultado de uma das etapas de pesquisa acerca da história dos hospitais em Salvador, $\mathrm{BA}$, financiada pelo $\mathrm{CNPq}$, que teve a participação de bolsistas de iniciação científica e alunos de pósgraduação. Seu objetivo é estudar, através da análise das condições ambientais do Sanatório Santa Terezinha, inaugurado em 1942, o planejamento efetuado por arquitetos modernistas quanto ao uso das condições de conforto ambiental como auxílio na cura da tuberculose, demonstrando a intenção de que a arquitetura participasse do processo curativo. Como metodologia, adotou-se o processo comparativo entre a edificação estudada e projetos de sanatórios europeus do período, detalhando, com processos tecnológicos atuais, os estudos de conforto ambiental feitos pelos arquitetos. Deve-se ressaltar que os estudos de conforto ambiental em edificações tiveram início exatamente nesse período, tratando-se, portanto, de procedimento inovador para a época.

Os sanatórios foram edificações idealizadas para o auxílio no combate à tuberculose, quando, no final do século XIX e início do século XX, experimentou-se mundialmente uma epidemia. Apesar de sua multicausalidade, pode-se apontar o veloz processo de urbanização e as condições precárias de vida, notadamente deficiências alimentares e de habitação, como fatores determinantes da rápida proliferação da doença. Segundo Quecedo $(2012$, p. 38), “[...] a tuberculose, mais tarde chamada peste branca, arrasa o continente europeu e chega, no princípio do século XX, a ser a primeira causa de mortalidade em toda Europa.".

Como seu contágio pode se processar por via aérea, a alta densidade populacional e deficientes condições de aeração são características físicas habitacionais indutoras da doença. Salvador, capital da Bahia, foi uma das cidades brasileiras onde a epidemia se abateu com maior intensidade. Na década de 1930, morriam, em média, 1.600 pessoas por ano de tuberculose nessa capital, que registrava o mais elevado índice de letalidade do Brasil - 400/100.000 habitantes (MACHADO, 2007). Apesar de a tendência à urbanização estar apenas iniciando-se no Brasil, naquela época a cidade de Salvador já concentrava uma população com baixas condições de renda, constituída de ex-escravos ou migrantes da zona rural, expulsos pelas periódicas secas do interior do Nordeste, os quais residiam em habitações precárias.

Como reação das autoridades sanitárias a esse mal, considerando a falta de medicamentos eficientes de combate à doença, a primeira providência foi o isolamento dos casos, como é procedimento comum nas epidemias. Para tanto, estabeleceram-se edificações isoladas, mediante aluguel de casas em sítios e fazendas (SANTOS, 2005).

Essa época era uma fase de transição entre o paradigma de causalidade das doenças infecciosas pelos chamados miasmas e as novas hipóteses de atuação dos micro-organismos, precedendo a descoberta dos antibióticos. Nesse período, a busca de soluções de melhor adequação ambiental era comum, com a defesa dos hospitais de tipologia pavilhonar, com limitação de doentes por enfermaria e favorecimento da ventilação e entrada do sol (NIGHTINGALE, 1863).

Apesar da descoberta do bacilo de Koch como o causador da doença, em 1882, e a pesquisa com vacinas, apenas em 1944 encontrou-se um antibiótico eficiente para a cura, tornando-se então desnecessária a internação (ROCHA, 2015).

No início do século XX, para o tratamento da tuberculose, foram feitas com sucesso experiências de exposição solar e exercícios respiratórios em ambientes livres de poluição, o que fez que as condições ambientais que favorecessem esses procedimentos se tornassem desejáveis nas edificações de saúde projetadas para esse fim.

No Brasil, no esforço nacional contra a tuberculose, foi criado em 1941 o Serviço Nacional de Tuberculose (SNT), e em 1946 foi instituída a Campanha Nacional Contra a Tuberculose (CNCT). Segundo Antunes, Waldman e Moraes (2000, p. 368):

A consolidação de grandes centros urbanos, em todas as regiões do país, reforçou antigas preocupações ante a associação da enfermidade com a privação e a iniquidade social, com os movimentos migratórios, com as precárias condições de habitação nas cidades e com a baixa efetividade dos programas de assistência e controle.

A matriz de edificações de saúde para o combate à doença incluía os preventórios, os dispensários e os sanatórios. Os preventórios tinham a função de acolher crianças filhas de pais acometidos de tuberculose. Essas crianças eram cuidadas por um tempo variável, até que pudessem voltar a seus lares. A função dos dispensários era a procura de focos de contágio, a difusão das noções de higiene e a prestação de assistência

166 Carvalho, A. P. A. de; Guedes, F. de J.; Souza, C. M. de J. 
médica e social aos doentes. Os sanatórios eram reservados para o isolamento e o tratamento continuado (BRASILEIRO, 2012). A tuberculose se transformou em um terror a ser enfrentado, e o isolamento dos doentes da comunidade era visto como uma obrigação do Estado.

\section{Referencial teórico}

A arquitetura de sanatórios representa uma etapa na evolução das tipologias hospitalares, iniciada com as hospedarias para viajantes e o atendimento caritativo. Inicialmente, o hospital era um abrigo para indigentes ou para aqueles que, com problemas de saúde, não tinham onde ficar. Era um local para a caridade e, mesmo, para a colocação de pessoas marginalizadas da sociedade, não necessariamente doentes (MIQUELIN, 1992; PEVSNER, 1979).

Nessas instituições, a condição ambiental não era importante, sendo os doentes colocados lado a lado, às vezes na mesma cama. $\mathrm{O}$ hospital medieval era um local para se aguardar a morte, para a segregação dos que não deveriam estar à vista, para os que ameaçavam a sociedade (FOUCAULT, 1984).

$\mathrm{Na}$ idade média, as epidemias assolavam periodicamente as comunidades urbanas, sendo o hospital um local de isolamento e vigilância, onde os acometidos dos mais diversos males eram colocados. Em Barcelona, por exemplo, cidade portuária do Mediterrâneo, que recebia visitantes de todo o mundo conhecido, tem-se notícia de onze episódios de epidemias no século XV (BETRAN, 1996).

A medicina como se conhece hoje não existia, sendo o espaço do hospital um simples galpão, onde se enfileiravam camas e onde a oração e o preparo para a morte eram mais importantes que a cura. Segundo Foucault (1984, p. 101), "O hospital que funcionava na Europa na Idade Média não era, de modo algum, um meio de cura [...]. Antes do século XVIII, o hospital era essencialmente uma instituição de assistência aos pobres. Instituição de assistência, como também de separação e exclusão [...]”.

Em relação à arquitetura, a forma em nave era a mais aplicada, havendo variações, quando ampliadas, para a criação de pátios internos, ou claustros, ou em naves cruzadas, com a intercessão constituindo-se em ponto de vigilância e controle (CARVALHO, 2009).

Apenas no século XVIII, quando a Europa experimentava o início da Revolução Industrial, houve uma mudança formal e funcional nos hospitais. Um acontecimento é considerado marcante nessa mudança: o incêndio do Hotel Dieu, o maior hospital de Paris. Essa tragédia comoveu a sociedade francesa da época, sendo solicitada à Academia de Ciências a apresentação de um projeto para um novo hospital. Para tanto, foi chamado o médico Jacques René-Tenon, que realizou visitas a instituições de internação pela Europa, propondo, em seu trabalho Memoires sur les Hopitaux de Paris (TENON, 1788), juntamente com o arquiteto Bernard Poyet, uma nova estrutura hospitalar em forma de pavilhões, onde haveria a limitação do número de pacientes por blocos e a segregação de doentes por tipo de ocorrência. Nesse trabalho, Tenon dava grande importância às questões relativas à ventilação, iluminação natural e espaço externo para a deambulação dos doentes que tivessem condições para tanto.

Durante o século XIX, portanto, o hospital passa da condição de ser apenas local para se aguardar a morte para ser uma "máquina de curar". Segundo Foucault (1984, p. 109), trata-se de uma total mudança paradigmática, em que "A arquitetura hospitalar torna-se um instrumento de cura de mesmo estatuto que um regime alimentar, uma sangria ou um gesto médico". A tipologia pavilhonar vai se impondo nas construções hospitalares, e é nesse contexto que se insere a criação dos sanatórios para o tratamento da tuberculose.

Até a descoberta da ação dos micro-organismos, acreditava-se que as doenças seriam causadas por miasmas - vapores deletérios emanados de locais sujos, onde a ventilação ou ação solar não atuava. Até a descoberta dos antibióticos não havia tratamento confiável para a cura de doenças contagiosas, sendo a questão ambiental colocada como a das mais importantes entre as condicionantes saudáveis para os doentes. O conceito de sanatório significava a criação de um ambiente onde o paciente seria isolado da comunidade, deixando de ser uma fonte de risco de contágio, e receber tratamento pelas novas condições a que era submetido.

A criação de sanatórios para o tratamento da tuberculose foi uma tendência no tratamento de saúde que atingiu todo o mundo ocidental. De acordo com Rocha (2015), o primeiro hospital com a finalidade específica de tratamento da tuberculose foi o Royal Sea Bathing Infirmary for Scrofula, fundado em 1791, na Inglaterra. Nessa instituição era defendida a terapia de exercícios respiratórios perto do mar.

Os sanatórios eram instituições de longa permanência com forte apelo hoteleiro, que necessitavam de amplas áreas externas para a deambulação, exercícios físicos, ar puro, sol e lazer. A prescrição dos banhos de sol era 
chamada helioterapia, sendo prescritas varandas para esse fim. A internação era provocada essencialmente pela necessidade de isolamento, e não pelo fato de o doente estar incapacitado de se locomover. Essas características indicavam a localização em áreas elevadas, vegetação circundante e sem poluição, o que implicava estar longe dos centros urbanos.

De acordo com Faget (1932, p. 2), em artigo da época, o sanatório tinha as seguintes vantagens:

Ventajas del sanatorio - Por muchas razones el sanatorio es el mejor sitio para tratamiento. Se encontrará allí el enfermo entre otros dolientes del mismo mal, y será más fácil animarlo en sus esfuerzos para reponerse. Recibirá también asistencia médica experta y enfermería especial. Tiene a su disposición los medios de un moderno departamento dietético. Se le ofrecen mayores medios de descanso físico y sosiego mental. El sanatorio moderno ha sido construido no tan sólo para comodidad, sino con mira a obtener aire puro en la mayor abundancia, y muchos de esos establecimientos poseen además la ventaja de un clima ideal. Si es necesaria, la helioterapia puede ser administrada allí bajo dirección médica avezada, y si se hallan indicados los beneficios de la colapsoterapia quirúrgica, serán ofrecidos por cirujanos torácicos de experiencia. Por fin, el enfermo aprenderá allí lecciones valiosas en higiene personal, y conocimientos de la naturaleza de su afección, que lo capacitarán para combatirla mejor, y le serán muy útiles después que regrese a su casa. (grifo nosso).

Como a arquitetura tinha participação decisiva no tratamento da doença, a maioria das edificações sanatoriais possuíam características similares, destacando-se:

(a) localização afastada da zona urbana mais densa, em cota topográfica alta e possibilidade de ventilação constante;

(b) favorecimento da ventilação cruzada, com a colocação de esquadrias em paredes opostas, induzindo formas alongadas e estreitas;

(c) incentivo ao banho de sol pelo estabelecimento de varandas, por vezes colocadas em forma escalonada;

(d) orientação estudada para o favorecimento da ventilação e da incidência solar;

(e) separação entre sexos, com estabelecimento de alas simétricas; e

(f) centralização do apoio e separação da circulação de serviço, de modo a permitir o atendimento das alas masculina e feminina.

A necessidade de colocar os aposentos dos doentes na melhor disposição relativamente ao sol e à ventilação conduziu ao uso de extensas varandas. Esse fator e a necessidade de separação das alas masculina e feminina conduziram a um partido arquitetônico que impunha a centralização dos espaços de apoio de uso comum, resultando em uma solução arquitetônica em planta simétrica, em forma de " $T$ " e variantes.

Um exemplo de uma arquitetura sanatorial que seguia esses preceitos, procurando ser participante do processo de cura, é o Paimio Sanatorium, em Turku, na Finlândia, projetado por Alvar Aalto, considerado um patrimônio mundial pela Unesco (Figura 1). Esse sanatório foi construído na década de 1930 e está localizado em uma zona não urbanizada, junto a um bosque (ANDERSON, 2010).

Sua planta demonstra o padrão usual dos sanatórios europeus, com formato alongado e acomodações dispostas de modo a permitir a ventilação cruzada, com grande varanda à frente e corredor de serviço ao fundo. A varanda servia para a utilização da chamada helioterapia.

Figura 1 - Planta do Paimio Sanatorium, em Turku, na Finlândia, projetado por Alvar Aalto

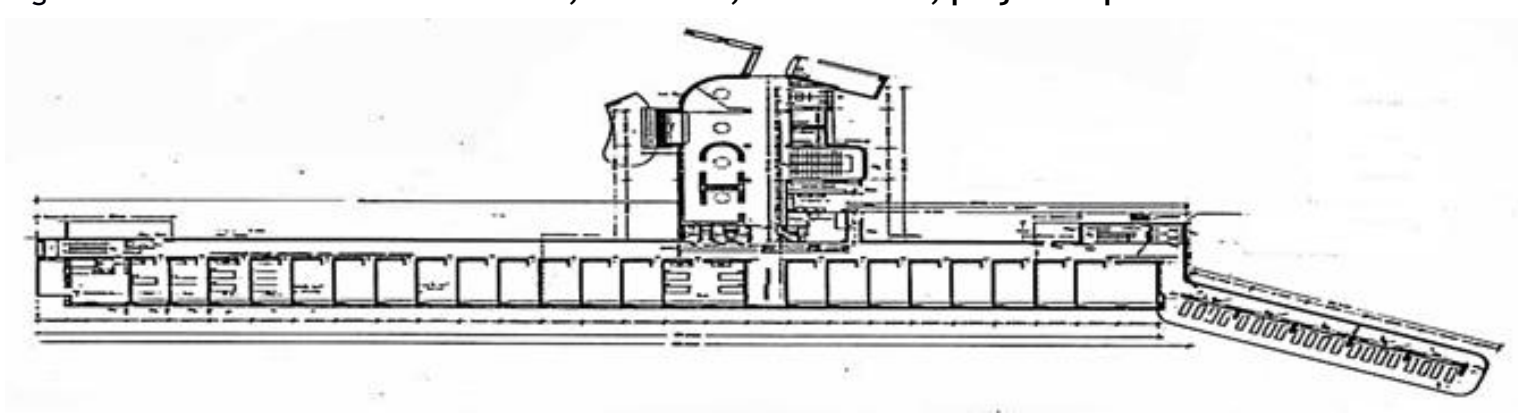

Fonte: Quecedo (2012).

168 Carvalho, A. P. A. de; Guedes, F. de J.; Souza, C. M. de J. 
Observa-se a centralidade das instalações de apoio. Nesse caso, possivelmente por razões culturais, não há a simetria da separação de sexo.

A forma adotada pelo Sanatório Santa Terezinha foi inspirada em modelos europeus, como o Hospital de Berna, Suíça (1930) (Figura 2), o Pavilhão de Tuberculose do Hospital de San Sebastian, Espanha (1933), e o Centro Sanatorial de Forli, na Itália (1934) (QUECEDO, 2012).

\section{Métodos}

A questão de investigação a que se buscou responder na presente pesquisa foi se os arquitetos modernistas envolvidos no projeto arquitetônico do Sanatório Santa Terezinha tinham conhecimento das condicionantes funcionais intervenientes em projetos europeus semelhantes da mesma época. O objetivo da presente pesquisa, portanto, foi determinar a intencionalidade dos autores do projeto arquitetônico do único sanatório para a tuberculose edificado em Salvador em seguir as características funcionais de projetos semelhantes europeus, que aproveitavam o ambiente edificado como instrumento de cura.

Para a solução da questão proposta, foi adotada como metodologia a comparação entre as condicionantes arquitetônicas prescritas para os sanatórios em exemplos europeus da época e as existentes no sanatório analisado. Foi, dessa forma, realizada pesquisa bibliográfica assistemática sobre a evolução da arquitetura hospitalar e as características formais dos sanatórios, utilizando-se referências recentes sobre o tema, tendose chegado à listagem especificada no referencial teórico.

Para a determinação da intencionalidade e conhecimento dos arquitetos, detalhou-se o planejamento relativo ao conforto ambiental da edificação, utilizando-se em relação ao Sanatório Santa Terezinha cadastro da situação atual, modelagem tridimensional e testes de incidência solar e de ventilação, com programas computacionais e observações in loco da implantação do edifício e das condições do entorno, constatando-se o ângulo preciso da orientação, a manutenção de massa vegetal, a ventilação e a incidência solar sem barreiras físicas de outras edificações.

Partiu-se da hipótese de que eram conhecidas por parte dos arquitetos do Sanatório Santa Terezinha todas as condicionantes funcionais determinadas pela arquitetura hospitalar europeia da época, não somente em relação à forma, mas também à orientação do edifício, principalmente no que tange aos sanatórios e ao tratamento da tuberculose, que se constituía no que havia de mais avançado em arquitetura hospitalar no período.

O cadastramento buscou demonstrar a adequação das características formais da edificação com o determinado pelos edifícios europeus de função semelhante. Os testes de incidência solar e de ventos foram essenciais para constatar se os autores do projeto realizaram a implantação do edifício obedecendo a estudos que buscavam maximizar sua utilização para fins terapêuticos.

A utilização de processos tecnológicos atualizados e mais precisos de análise, não existentes na época de execução do projeto arquitetônico da edificação, possibilitou a constatação de eventuais imprecisões ou erros dos projetistas, considerando as premissas curativas estabelecidas pela chamada helioterapia e a ventilação.

Figura 2 - Hospital de Berna, Suíça, 1930, que utilizava a helioterapia e tinha um partido arquitetônico semelhante ao do Sanatório Santa Terezinha
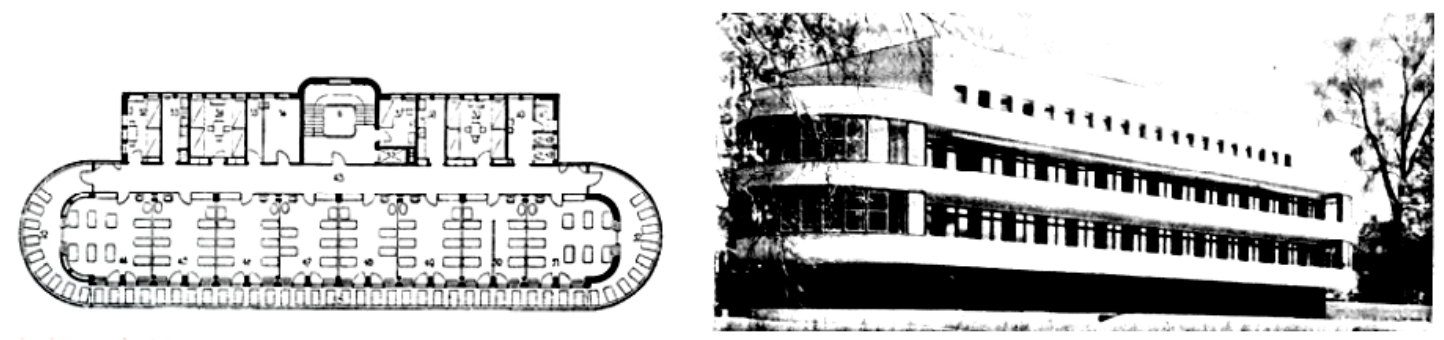

Fonte: Quecedo (2012). 


\section{Resultados e discussões}

O formato com extremidades arredondadas do Sanatório Santa Terezinha propiciava melhor aproveitamento da extensa varanda para o banho de sol. Dessa forma se adaptaria mais eficientemente às diversas estações do ano. A forma alongada, com circulações em lados opostos das enfermarias e o posicionamento das esquadrias, propiciava a ventilação cruzada eficiente.

O Sanatório Santa Terezinha foi construído entre 1937 e 1942, tendo como autores do projeto arquitetônico o arquiteto carioca Jorge Machado Moreira (1904-1992), que possuía experiência na área hospitalar, e Diógenes de Almeida Rebouças (1914-1994), arquiteto baiano que cuidou dos detalhes de aprovação local e acompanhamento da construção (ANDRADE JUNIOR, 2011).

Jorge Moreira era considerado um modernista clássico, que dava destaque às questões funcionais da arquitetura, sendo seguidor fiel das diretrizes de Le Corbusier. Entre seus projetos mais conhecidos na área da saúde destacam-se o Hospital das Clínicas da Faculdade de Medicina da Universidade Federal do Rio Grande do Sul e um centro de puericultura no Rio de Janeiro. Foi um dos professores do destacado Curso de Planejamento de Hospitais, promovido pelo Instituto dos Arquitetos em 1953, em São Paulo, primeiro do gênero no Brasil (JORGE MOREIRA, 2020).

Diógenes Rebouças foi um conceituado arquiteto modernista baiano que prestava serviços regulares à Construtora Norberto Odebrecht, responsável pela construção do sanatório. Foi professor da Faculdade de Arquitetura da Universidade Federal da Bahia de 1952 a 1984 (DIÓGENES REBOUÇAS, 2020).

O estilo da edificação é marcadamente modernista, com traços geométricos, sendo um dos ícones da arquitetura baiana, em processo de tombamento. De acordo com Bierrenbach (2017), “[...] seu volume é demarcado por linhas horizontais e extremidades curvas [...]" (Figura 3). Está localizado na cidade de Salvador, no bairro do Pau Miúdo.

A implantação do hospital se deu em área elevada da cidade, que, inicialmente, era isolada, mas hoje possui edificações com gabarito baixo, sem barreiras que atrapalhem a incidência dos raios solares ou a boa captação dos ventos. O local ainda possui grande área arborizada, que favorece um microclima agradável e ventilado.

O edifício principal do sanatório possui cinco pavimentos, sendo o térreo reservado para serviços administrativos e ambulatoriais, o primeiro e o segundo pavimentos para enfermarias de quatro ou seis leitos, e o terceiro e o quarto pavimentos, que têm largura menor, para quartos individuais. Suas enfermarias e quartos são colocados de forma contígua, com acesso em corredor monocarga - isto é, com compartimentos apenas de um lado. Como resultado desse partido, sua volumetria é marcadamente longitudinal, no sentido noroeste e sudeste, apresentando comprimento máximo de $110 \mathrm{~m}$ e largura de $10 \mathrm{~m}$ (SOUZA; BARRETO, 2011) (Figura 4).

Figura 3 - Vista do Sanatório Santa Terezinha na época da inauguração

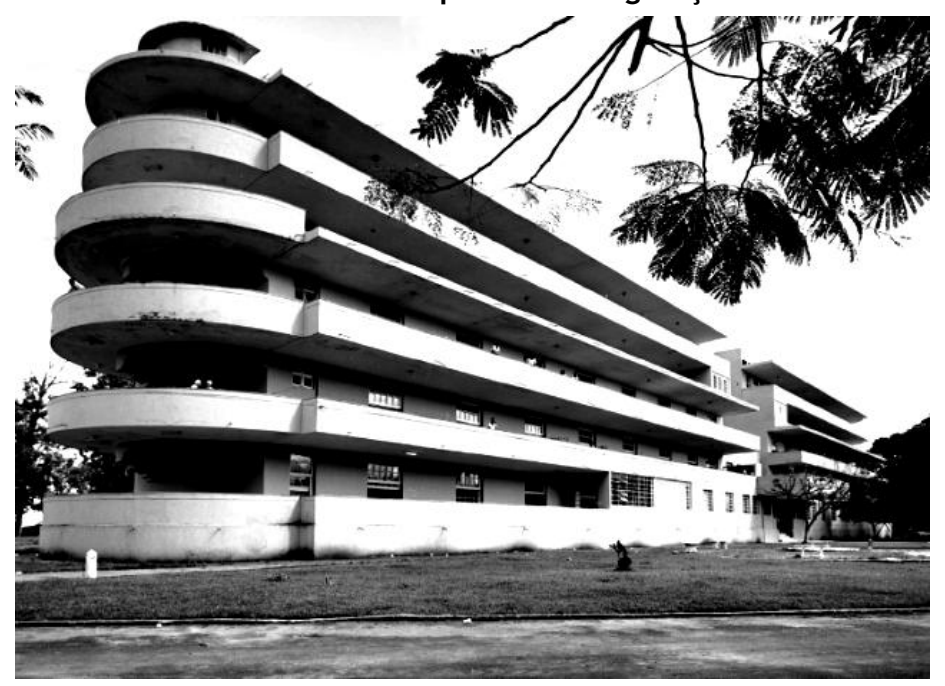

Fonte: Souza e Barreto (2011).

170 Carvalho, A. P. A. de; Guedes, F. de J.; Souza, C. M. de J. 
Figura 4 - Esquema de planta do segundo piso do edifício principal do Sanatório Santa Terezinha

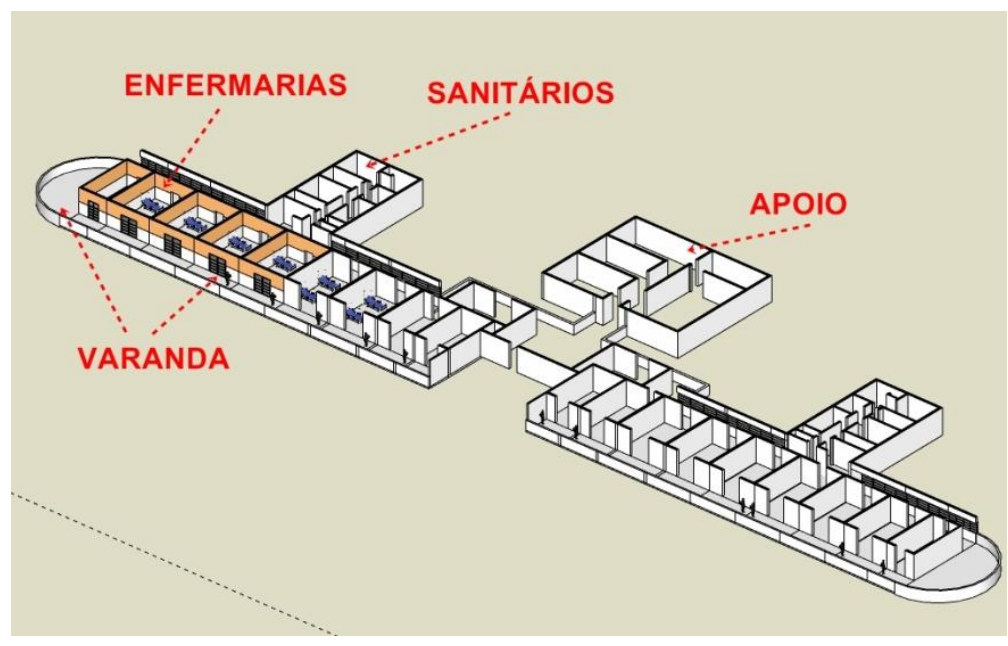

Essa disposição favorece o acesso a uma grande varanda, que proporciona a incidência solar em períodos controlados. Ligados ao corpo principal do edifício, existem três blocos, sendo duas prumadas de sanitários e uma de apoio de enfermagem.

As varandas permitem a incidência solar ao longo das manhãs e o bloqueio nos horários de maior temperatura. O hospital foi projetado para a utilização dos princípios da ventilação cruzada e da helioterapia, características prescritas pelos modelos europeus. Para atender a essa demanda, o edifício foi implantado em posição condizente com as direções de sol e ventos. Conforme corte esquemático (Figura 5), pode-se observar que os dois andares superiores são mais estreitos, sendo reservados para a internação em quartos individuais, próprios para o isolamento de casos mais graves. Nestes andares, há diminuição também no sentido longitudinal, como se pode ver na Figura 2, o que torna as varandas das extremidades do terceiro andar mais largas, com a possibilidade maior de incidência solar.

Ao longo dos anos de operação, o hospital passou por várias atualizações, além de construções de anexos, sendo responsável pelo tratamento de diversas doenças respiratórias. A tuberculose deixou de apresentar grandes riscos à população, e como o tratamento ambulatorial se tornou mais eficaz, diminuindo o número de mortes, passou a não haver mais a necessidade de uma instituição de internação destinada somente ao cuidado dessa doença.

\section{Análise das condições de incidência solar}

A norma técnica de Desempenho Térmico de Edificações, NBR 15220 (ABNT, 2005a) estabelece o Zoneamento Bioclimático Brasileiro. Nessa norma são feitas recomendações de diretrizes construtivas e detalhamento de estratégias de condicionamento térmico passivo que aperfeiçoam o desempenho das edificações através de sua melhor adequação climática.

A Zona Bioclimática 8, em que se encontra a cidade de Salvador, possui as recomendações técnicoconstrutivas de adoção de sombreamento e grandes aberturas, para permitir a entrada de ventos, conforme carta bioclimática e indicações da NBR 15220 (ABNT, 2005a).

Ao redor do Sanatório Santa Terezinha existem massas de vegetação que influenciam no condicionamento do microclima. A vegetação, por conta do fenômeno da evapotranspiração, altera o nível da umidade local, podendo aumentá-lo. As áreas vegetais, além disso, refletem menor quantidade de radiação, o que contribui para a diminuição do calor. A massa de vegetação circundante ao hospital, portanto, atua proporcionando a regulação da temperatura ambiente.

A fachada principal da edificação está orientada para nordeste. Nessa fachada se encontram as varandas, ambientes que permitem a incidência solar no período de menor temperatura, como se percebe na análise da Figura 6.

A forma arquitetônica do hospital, juntamente com a disposição de seus espaços, permite que todos os alojamentos de pacientes tenham ligação direta com o exterior, condição que facilita a exploração da luz e a ventilação cruzada para o conforto e uso com fins terapêuticos. 
Figura 5 - Corte esquemático do edifício principal do Sanatório Santa Terezinha

Fonte: Matos e Otremba (2018).

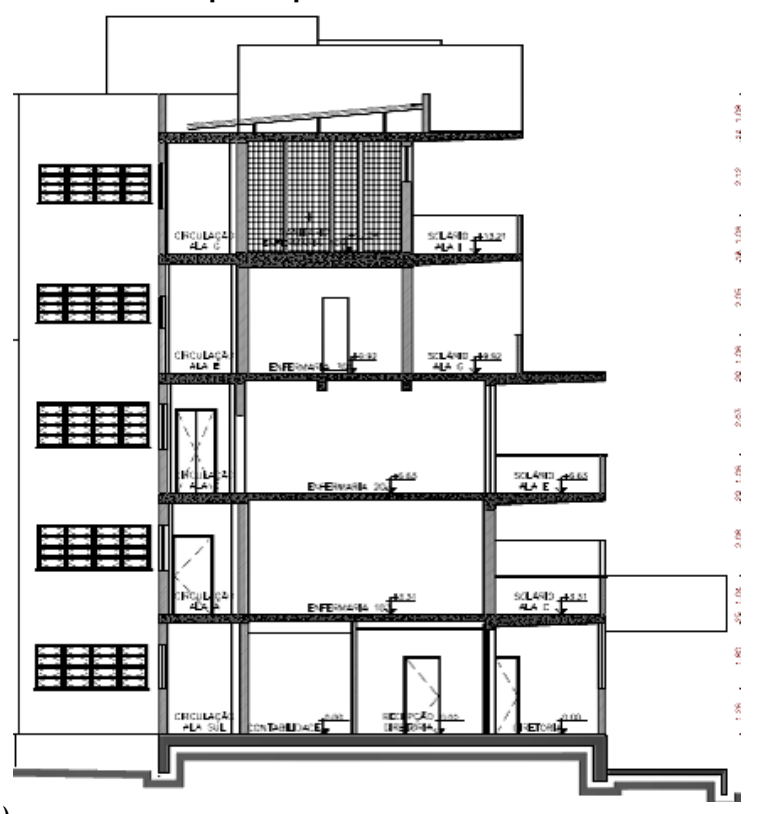

Figura 6 - Orientação e percurso solar na fachada principal do Sanatório Santa Terezinha

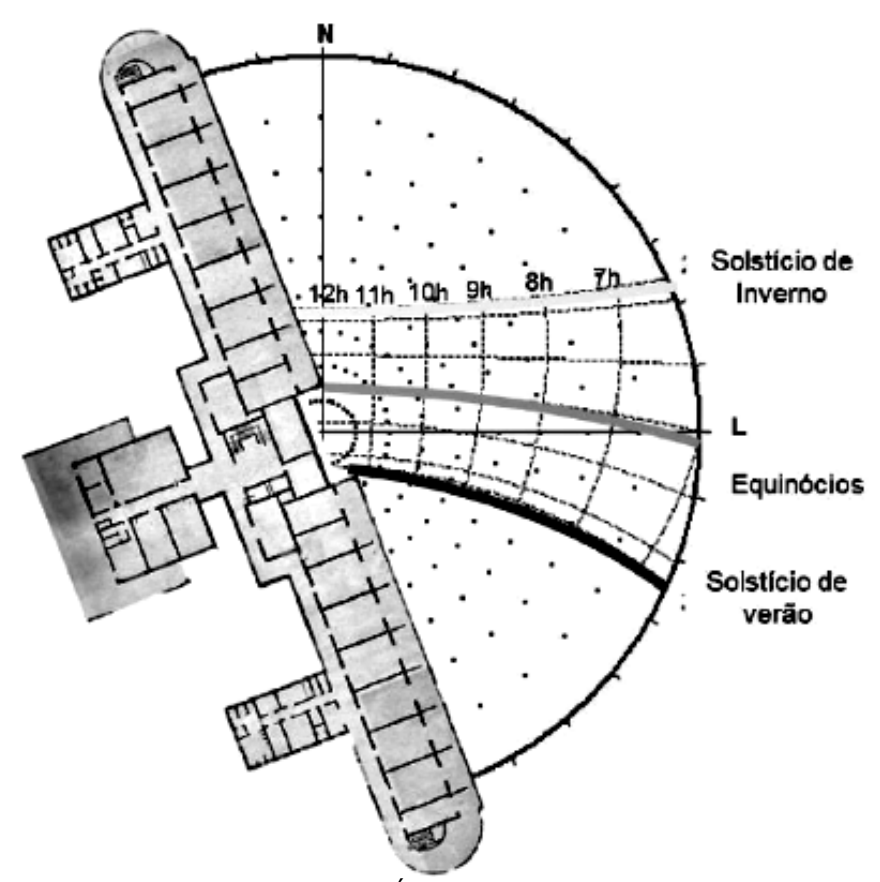

Fonte: gerada pelo programa Analysis SOL-AR (LABORATÓRIO..., 2019).

A varanda de cada pavimento é sombreada por conta da laje do pavimento superior. As varandas proporcionam, assim, os banhos de sol ao longo das manhãs e o bloqueio nos horários de maior temperatura.

Observa-se na Figura 7 estudos do caminhamento solar em horários diversos, na varanda da fachada principal da edificação, efetuado com o software Sketchup (2019), demonstrando a forma de incidência nos solstícios de verão e inverno, com o percurso maior do sol no período de menor calor.

A orientação do edifício, portanto, foi colocada de forma a permitir o uso da helioterapia diariamente, durante todo o ano, proporcionando condição ambiental adequada à finalidade da edificação. A orientação nordeste da fachada maximiza o período solar nas estações chuvosas, o que oferece maior probabilidade de incidência e uso curativo.

172 Carvalho, A. P. A. de; Guedes, F. de J.; Souza, C. M. de J. 
Figura 7 - Caminhamento do sol nas varandas do sanatório Santa Terezinha nos solstícios de inverno e verão

\section{Solstício de Inverno (21/06)}

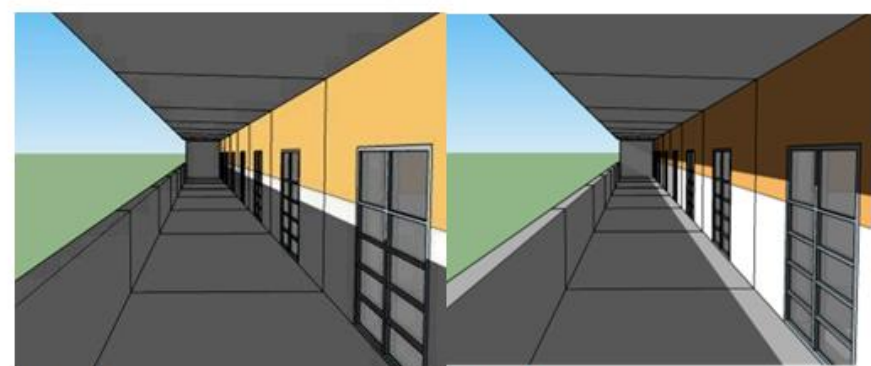

$06: 00 \mathrm{~h}$

$08: 00 \mathrm{~h}$

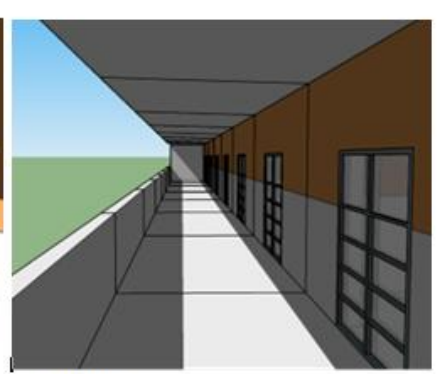

$10: 00 \mathrm{~h}$

Solstício de Verão (21/12)

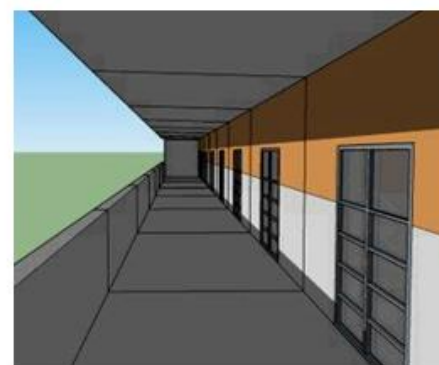

06:00 h

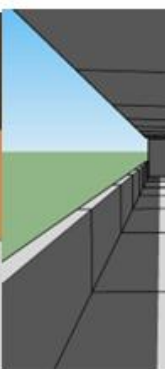

$08: 00 \mathrm{~h}$

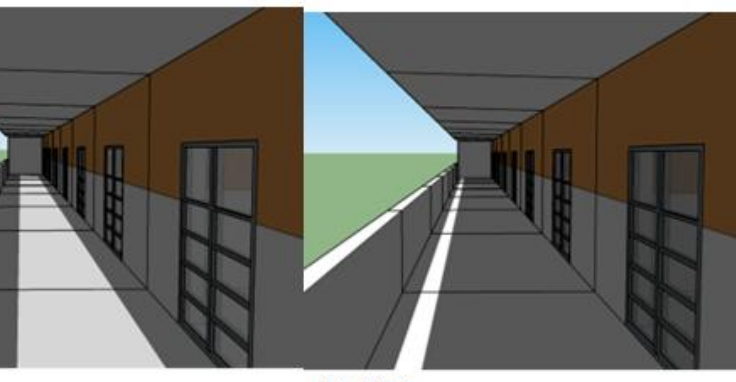

$10: 00 \mathrm{~h}$

Fonte: gerada com o programa Skechup (2019).

\section{Análise das condições de ventilação}

A qualidade do ar em edificações de saúde se trata de característica amplamente estudada, notadamente naquelas que abrigam doenças contagiosas. Há, inclusive, a norma NBR 7256 (ABNT, 2005b), que estabelece o tratamento do ar nesses edifícios, indicando a filtragem do ar em áreas de isolamento de doenças com possibilidade de transmissão aérea, como é o caso da tuberculose. Na época do projeto e construção do Sanatório Santa Terezinha, não havia essa possibilidade, sendo essencial a utilização da ventilação cruzada.

A ventilação cruzada é uma estratégia utilizada com o objetivo de se obter o condicionamento térmico de uma edificação através da movimentação do ar no interior do edifício. O fluxo de ar retira o excesso de calor acumulado nos ambientes internos, aquecidos pelos usuários e outras fontes, promovendo a troca térmica entre os ambientes. Em climas quentes e úmidos, como em Salvador, torna-se essencial para o conforto térmico, na maior parte do ano, o aproveitamento da ventilação natural.

Essa renovação de ar permite também a higienização do ambiente, retirando partículas sólidas e odores indesejáveis, reduzindo a concentração de $\mathrm{CO}_{2}$ e de micro-organismos. Os ventos diminuem, além disso, o excesso de vapor d'água no ar interno, regulando a temperatura e diminuindo a probabilidade de contaminação da tuberculose por via aérea (CARVALHO, 2017; DE QUADROS, 2016).

Pelo estudo da rosa dos ventos para Salvador (Figura 8), observam-se as direções incidentes no hospital, indicando maior fluxo do vento leste no solstício de verão. A fachada nordeste, para onde se abrem as varandas e as enfermarias, é beneficiada por essa ventilação, fato que garante o condicionamento térmico, combatendo o desconforto gerado pela alta umidade da cidade, que varia em torno de $80 \%$ durante todo o ano.

O melhor ângulo de incidência da ventilação é importante para que se alcancem bons resultados em termos de atuação sobre todas as áreas dos cômodos. Chu, Chen e Chen (2011) realizaram um estudo que analisou a influência da taxa de ventilação de edifícios em relação ao ar interno, com modelos apresentando aberturas em somente um e nos dois lados, sob várias direções do vento. Concluíram que a taxa de entrada do ar fresco, com a varredura de todas as áreas nos cômodos, é superior quando atrelada à existência de um ângulo 
entre $45^{\circ}$ e $67,5^{\circ}$ em relação à fachada e à direção do vento predominante, devendo a edificação ter duas aberturas opostas. Essa faixa de ângulos provoca maiores diferenças de pressões externas e internas, aumentando a velocidade de circulação do ar. Nessas condições, o fluxo de ar percorre todo o ambiente interno, evitando pontos de estagnação e proporcionando a eficiente passagem do ar fresco.

A orientação da fachada do edifício estudado, exatamente a $67,5^{\circ}$ do vento leste - predominante nos meses de maior calor - e a disposição dos espaços internos do hospital e suas esquadrias possibilitam a fluidez da circulação do ar, facilitando a ventilação cruzada, estratégia que estimula o fluxo pelos ambientes e entre o ambiente externo e o ambiente interno, induzindo um efeito de troca total do ar interno dos quartos e enfermarias.

A ventilação natural passiva, como estratégia de projeto, pode ser obtida por conta da incidência dos ventos nas edificações ou do efeito chaminé (MORAIS; LABAKI, 2017). Para avaliar o comportamento da interação da ventilação natural, mais especificamente o impacto da ventilação cruzada, com o conforto térmico experimentado por usuários do hospital, foi realizado um mapeamento qualitativo das linhas de escoamento da ventilação nos ambientes internos do hospital.

A simulação foi realizada pela metodologia da dinâmica de fluidos computacional (CFD - Computer Fluid Dynamics), método no qual a geometria de um modelo existente é analisada como sendo uma rede de nós (ANDERSON, 1995). Com base nos parâmetros de entrada que a edificação real experimenta, a rede é utilizada para determinar o funcionamento do modelo. Os resultados do teste CFD são vetores, logo podem ser analisados quanto a sua orientação (qualitativamente) e velocidade (quantitativamente), fator que possibilita a esse método resultados com uma precisão superior àqueles apresentados por outros mais simplificados.

O software escolhido para a realização dos testes de fluxo do vento leste foi o AutoDesk Flow Design (2019), no qual foi aplicado o modelo tridimensional do hospital, executado no software Sketchup (2019), feito com base em seu cadastramento. Ressalta-se, no entanto, que a simulação se vale de três hipóteses simplificadoras:

(a) a ventilação natural foi considerada apenas como sendo gerada pela diferença de pressão ocasionada pela ação dos ventos na edificação;

(b) o pavimento de estudo foi considerado isolado para fins de simulação da ventilação interna; e

(c) não foi avaliada a interação da topografia e edificações vizinhas.

Figura 8 - Rosa dos ventos de Salvador no solstício de verão aplicada ao Sanatório Santa Terezinha

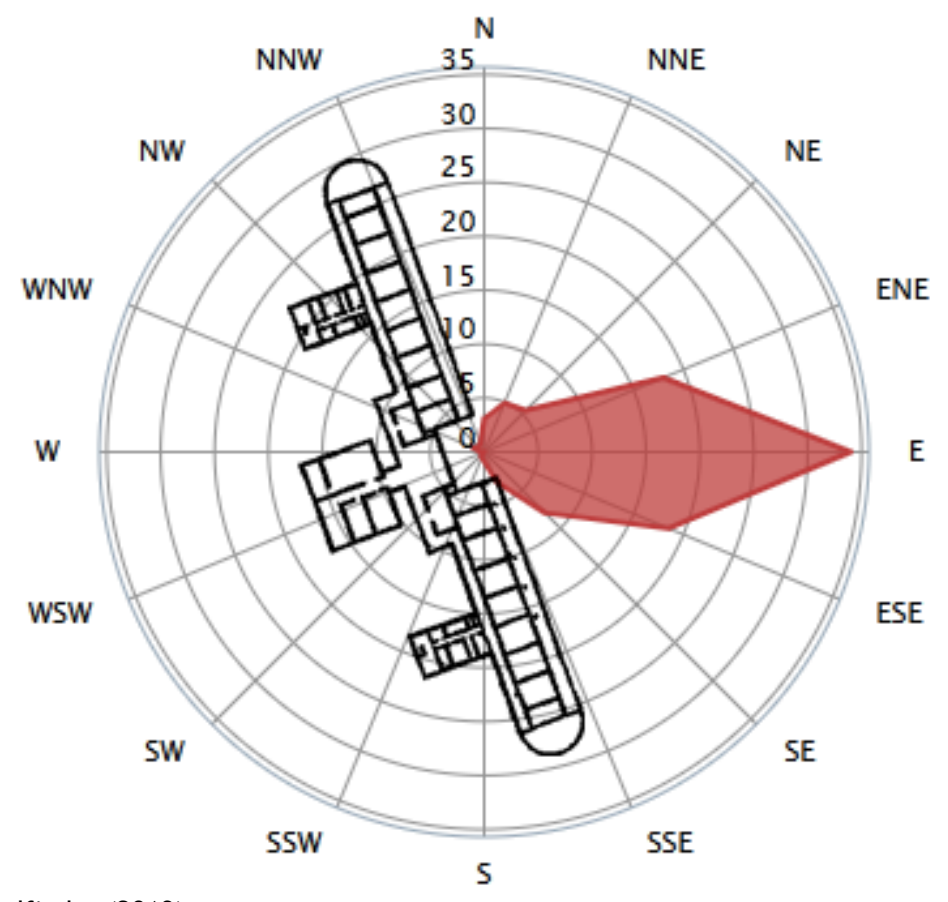

Fonte: baseada em Windfinder (2019).

174 Carvalho, A. P. A. de; Guedes, F. de J.; Souza, C. M. de J. 
Devido a essas simplificações, somente foi possível a representação dos resultados qualitativamente (imagem de caracterização das linhas de fluxo do vento nos ambientes internos).

O período adotado para o mapeamento das linhas de escoamento corresponde aos meses com as médias de temperatura anuais mais quentes do ano (outubro a abril). A direção dominante do vento foi leste $\left(67,5^{\circ}\right)$, de acordo com observações feitas entre outubro de 2002 e abril de 2019, diariamente das 7 às 19 horas, hora local, na estação meteorológica localizada no aeroporto da cidade de Salvador, informado pela página Windfinder (2019).

Com o resultado obtido (Figura 9), pode-se observar, em planta, o modelo do Sanatório Santa Terezinha com a distribuição qualitativa das linhas do escoamento do vento em seu interior, que indicam a comprovação da ocorrência do efeito de ventilação cruzada.

A ventilação cruzada ocorre no hospital com a penetração do vento através das varandas, enfermarias e corredor. Na simulação notam-se pontos de diferentes concentrações de linhas de fluxo de vento, que se dão devido à diferença nas dimensões das esquadrias adotadas no edifício.

Como observado nas simulações, a configuração do Sanatório proporciona uma boa distribuição de fluxo de vento interno, que realiza uma varredura eficiente nos compartimentos de alojamento dos pacientes, apesar de haver apenas passagem através das portas.

\section{Conclusão}

Ao se avaliarem as características de implantação da edificação estudada, fica claro que as decisões projetuais tomadas pelos arquitetos modernistas levaram em consideração as variações climáticas ao longo do ano na cidade de Salvador, procurando auxiliar no processo de restabelecimento dos pacientes, segundo o conhecimento científico da época.

A partir desse conhecimento, os arquitetos utilizaram o modelo europeu e propuseram uma edificação com predomínio do comprimento longitudinal, de modo a proporcionar a todos os compartimentos de permanência de doentes acesso direto a uma grande varanda, para a aplicação da chamada helioterapia. Essa solução também facilita a ventilação cruzada, proporcionando maior conforto e diminuição da quantidade de partículas sólidas, vapor d’água e micro-organismos no ar. O ângulo de implantação das varandas e aberturas frontais, a $67,5^{\circ}$ do leste, apesar de não ser conhecida a faixa de melhor posicionamento na época, atende às diretrizes atuais, conforme foi demonstrado.

Figura 9 - Fluxo do vento predominante no verão, no interior das enfermarias do Sanatório Santa Terezinha

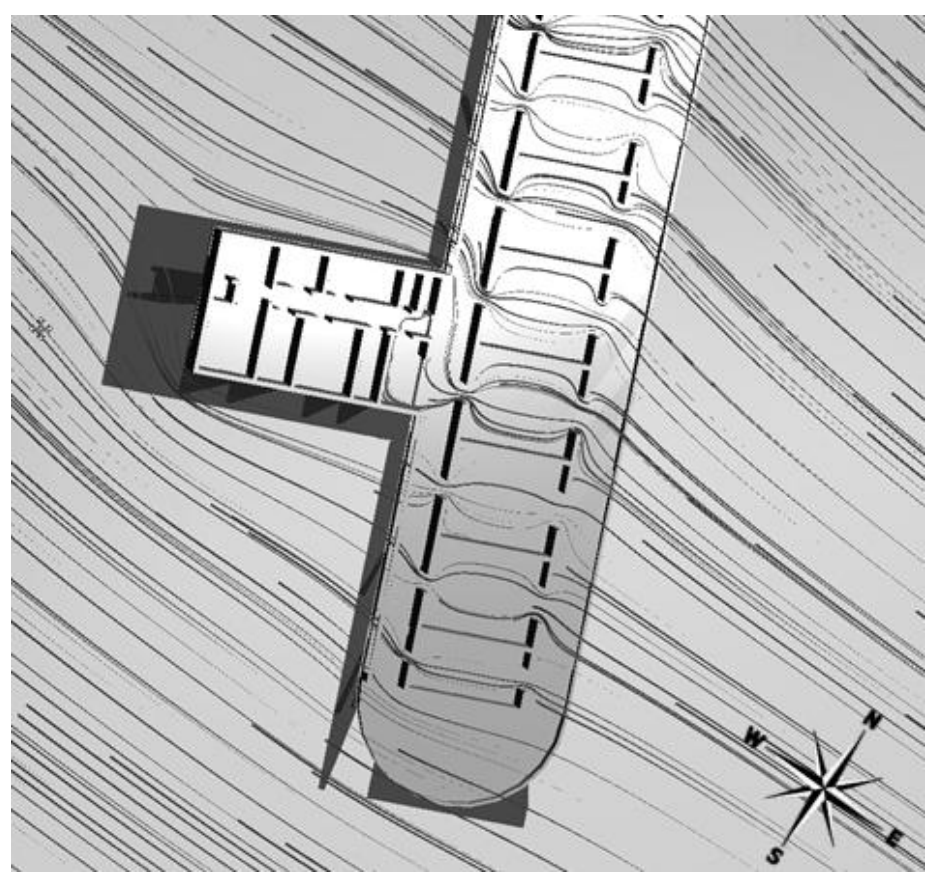

Fonte: baseado em AutoDesk Flow Design (2019). 
O conforto ambiental é obtido a partir da função original do Sanatório, que utiliza a luz e a ventilação natural como elementos de auxílio à cura. Pela análise geométrica e constatação empírica, observou-se grande precisão do projeto, tanto na escolha da forma e solução espacial interna, quanto na implantação. Havia, portanto, conhecimento dos projetistas sobre todas as nuances e detalhes do aspecto curativo dos sanatórios, adaptando-as às condições climáticas e ambientais da região.

Conclui-se que a edificação teve orientação e forma cuidadosamente estudadas, de modo a proporcionar as melhores condições ambientais para o tratamento da tuberculose pulmonar na época, constituindo-se em um exemplo claro da utilização da arquitetura como participante do processo terapêutico em relação à doença, como se fazia em relação aos modelos europeus.

Com o avanço técnico-científico do setor de saúde, a questão arquitetônica reduziu seu grau de importância, resultando na idealização de projetos hospitalares dependentes de meios artificiais de conforto ambiental, responsáveis pela maior parte do gasto energético. Esse procedimento está sendo atualmente reavaliado, e o Sanatório Santa Terezinha constitui-se em um exemplo histórico do uso do ambiente construído como auxiliar na cura das doenças, quando não havia procedimentos mais eficazes.

Como sugestão para pesquisas posteriores, seria interessante a constatação do índice de letalidade da tuberculose entre internados no Sanatório no período anterior ao uso dos antibióticos.

\section{Referências}

ANDERSON, D. Humanizing the hospital design. Canadian Medical Association Journal, v. 182, n. 11, 2010.

ANDERSON, J. Computational fluid dynamics. Nova York: McGraw-Hill, 1995.

ANDRADE JÚNIOR, N. V. de. Arquitetura moderna e as instituições de saúde na Bahia nas décadas de 1930 a 1950. In: SOUZA, C. M. C. de; BARRETO, M. R. N. (org.). História da saúde na Bahia: instituições e patrimônio arquitetônico (1808-1958). Barueri: Manole, 2011.

ANTUNES, J. L. F.; WALDMAN, E. A.; MORAES, M. de. A tuberculose através dos séculos: ícones canônicos e signos do combate à enfermidade. Ciência \& Saúde Coletiva, v. 5, n. 2, p. 367-379, 2000.

ASSOCIAÇÃO BRASILEIRA DE NORMAS TÉCNICAS. NBR 15220: desempenho térmico de edificações, parte 3: zoneamento bioclimático brasileiro e diretrizes construtivas para habitações unifamiliares de interesse social. Rio de Janeiro, 2005a.

ASSOCIAÇÃO BRASILEIRA DE NORMAS TÉCNICAS. NBR 7256: tratamento do ar em estabelecimentos de saúde. Rio de Janeiro, 2005b.

AUTODESK FLOW DESIGN. Autodesk. Disponível em: https://www.autodesk.com/education/freesoftware/flow-design. Acesso em: 2 jun. 2019.

BETRÁN, J. L. La peste em Barcelona de los Austrias. Lleida: Milenio, 1996.

BIERRENBACH, A. C. de S. Os traços das arquiteturas modernas de saúde em Salvador. Cadernos de Arquitetura e Urbanismo, v. 24, n. 34, 2017.

BRASILEIRO, C. Arquitetura antituberculose em Pernambuco: um estudo analítico dos dispensários de tuberculose do Recife (1950-1960) como instrumentos de profilaxia da peste branca. Recife, 2012. Dissertação (Mestrado em Desenvolvimento Urbano) - Programa de Pós-Graduação em Desenvolvimento Urbano, Departamento de Arquitetura e Urbanismo, Universidade Federal de Pernambuco, Recife, 2012.

CARVALHO, A. P. A. La arquitectura de los hospitales en Barcelona hasta la expansión modernista. Salvador: Quarteto, 2009.

CARVAlHO, A. P. A. O edifício doente e o edifício saudável. Sustinere, v. 5, n. 1, p. 135-152, 2017.

CHU, C. R.; CHEN, R. H.; CHEN, J. W. A laboratory experiment of shear-induced natural ventilation. Energy and Buildings, v. 43, n. 10, p. 2631-2637, oct. 2011.

DE QUADROS, B. M. Ventilação natural para o conforto térmico e renovação do ar em ambientes de internação hospitalar. Florianópolis, 2016. Dissertação (Mestrado em Arquitetura) - Programa de PósGraduação em Arquitetura e Urbanismo, Universidade Federal de Santa Catarina, Florianópolis, 2016.

176 Carvalho, A. P. A. de; Guedes, F. de J.; Souza, C. M. de J. 
DIÓGENES REBOUÇAS (verbete). In: ENCICLOPÉDIA Itaú Cultural de Arte e Cultura Brasileiras. São Paulo: Itaú Cultural, 2020. Disponível em: http://enciclopedia.itaucultural.org.br/pessoa444885/diogenesreboucas. Acesso em: 9 jan. 2020.

FAGET, G. H. Tendencias modernas en el tratamiento de la tuberculosis pulmonar. Boletin de la Oficina Sanitária Panamericana, Washington, v.76, ago. 1932. Disponível em: http://hist.library.paho.org/English/PUB/PBOS076.pdf. Acesso em: 9 jan. 2020.

FOUCAULT, M. Microfísica do poder. 4. ed. Rio de Janeiro: Graal, 1984.

JORGE MOREIRA (verbete). In: BRASIL ARTES ENCICLOPEDIAS. Disponível em: http://www.brasilartesenciclopedias.com.br/nacional/moreira_jorge.html. Acesso em: 9 jan. 2020.

LABORATÓRIO DE EFICIÊNCIA ENERGÉTICA EM EDIFICAÇÕES EM EDIFICAÇÕES. Analysis Sol-Ar. Disponível em: http://www.labeee.ufsc.br/downloads/softwares/analysis-sol-ar. Acesso em: 2 jun. 2019.

MACHADO, A. de S. A história da pneumologia na Bahia: tributo ao professor César Augusto de Araújo. Gazeta Médica Bahia, v. 77, n. 2, p. 195-209, jul./dez. 2007.

MATOS, L.; OTREMBA, G. Cadastro hospital especializado Octávio Mangabeira. 2018. Plantas em formato DWG.

MIGUELIN, L. C. Anatomia do edifícios hospitalares. São Paulo: CEDAS, 1992.

MORAIS, J. M. da S. C.; LABAKI, L. C. CFD como ferramenta para simular ventilação natural interna por ação dos ventos: estudos de caso em tipologias verticais do "Programa Minha Casa, Minha Vida". Ambiente Construído, Porto Alegre, v. 17, n. 1, p. 223-244, jan./mar. 2017.

NIGHTINGALE, F. Notes on hospitals. 3. ed. London: Longman, 1863.

PEVSNER, N. Historia de las tipologíasarquitectónicas. Barcelona: Gustavo Gili, 1979.

QUECEDO, C. R. Arquitectura terapéutica: el Sanatório Antituberculoso Pulmonar. Valladolid, 2012. Tese (Doutorado em Arquitectura) - Departamento Teoría de La Arquitectura y Proyetos Arquitectónicos, Universidade de Valladolid, Valladolid, 2012.

ROCHA, D. F. Arquitetura sanatorial: do projeto à reabilitação. Covilhã, 2015. Dissertação (Mestrado em Engenharia) - Curso de Engenharia, Universidade de Beira, Covilhã, 2015.

SANTOS, M. E. P.Entre os muros da exclusão: Hospital São Cristóvão dos Lázaros. Salvador, 2005. Dissertação (Mestrado em Arquitetura) - Faculdade de Arquitetura da Universidade Federal da Bahia, Salvador, 2005.

SKETCHUP. [Desenho]. Disponível em: www.sketchup.com. Acesso em: 2 jun. 2019.

SOUZA, C. M. C. de; BARRETO, M. R. N. (org.). História da saúde na Bahia: instituições e patrimônio arquitetônico (1808-1958). Barueri: Manole, 2011. Anexo V15.

TENON, J. R. Memoires sur les hôpitaux de Paris. Paris: De Límprimerie de Ph-D Pierres, Premier Imprimeur Ordinaire du Roi, 1788. Disponível em: https://gallica.bnf.fr/ark:/12148/bpt6k567231/f545.image. Acesso em: 2 jun. 2019.

WINDFINDER. Previsões de vento. Disponível em: https://pt.windfinder.com. Acesso em: 2 jun. 2019.

\section{Agradecimentos}

Agradecemos ao CNPq pelo apoio recebido. 


\section{Antonio Pedro Alves de Carvalho}

Faculdade de Arquitetura | Universidade Federal da Bahia | Rua Caetano Moura, 121 | Salvador - BA - Brasil | CEP 40210-905 | Tel.: (71) 3283-5898 | E-mail: pedro@ufba.br

\section{Félix de Jesus Guedes}

Faculdade de Arquitetura | Universidade Federal da Bahia | E-mail: felixjguedes@gmail.com

\section{Cleiton Marques de Jesus Souza}

Faculdade de Arquitetura | Universidade Federal da Bahia | E-mail: cleitonmjs@gmail.com

\section{Ambiente Construído}

Revista da Associação Nacional de Tecnologia do Ambiente Construído

Av. Osvaldo Aranha, $99-3^{\circ}$ andar, Centro

Porto Alegre - RS - Brasil

CEP 90035-190

Telefone: +55 (51) 3308-4084

Fax: +55 (51) 3308-4054

www.seer.ufrgs.br/ambienteconstruido

E-mail: ambienteconstruido@ufrgs.br

178 Carvalho, A. P. A. de; Guedes, F. de J.; Souza, C. M. de J. 